\title{
THE CONTRIBUTION OF GRIP STRENGTH AND WAIST FLEXIBILITY ON THE ACCURACY OF FLAT SERVICE FOR TENNIS PLAYERS OF PTL UNP
}

\author{
Kamal Firdaus \\ Padang State Uni versity, Komp. Parupuk Raya B.36 Tabing Padang West Sumatera 25171 \\ dr. Kamalfirdaus.mkes.aifo@gmail.com
}

\begin{abstract}
Problem of this research was derived from the observation which the researcher found in the field whether in training or competition. There are still many tennis players not able to do the flat service well and properly. This can be seen from the result of flat service done less maximum. The purpose of the research was to find out how big the contribution of the grip strength and waist flexibility on the accuracy of flat service for tennis players of PTL UNP.
\end{abstract}

Type of the research was correlational research. The population of the research was all tennis players of PTL UNP which consisted of 35 people. The sample in this research was taken by using purposive sampling in which it was taken based on the purpose or the research need. Therefore, the sampel of the research was male players who followed a training in the tennis training club of UNP. They are around 18-24 years old that totaled 20 people. This research was done at PTL UNP club. The grip strength data of PTL UNP tennis players were taken by using hand grip dynamometer test. The waist flexibility data were taken by flexiometer test and the accuracy of flat service data were taken from the players' accuracy of flat service.

Based on the data analysis, some results were obtained: (1) there was a contribution between the grip strength and the accuracy of flat service, in which the contribution was $62.1 \%$. (2) there was a contribution between the waist flexibility and the accuracy of flat service, in which the contribution was $62.1 \%$. (3) there was a contribution between the grip strength and waist flexibility on the accuracy of flat service, in which the contribution was $68.3 \%$. It can be concluded that the grip strength and waist flexibility contribute on the accuracy of flat service.

\section{A. Background of the Problem}

The improvement and development of technology nowadays has covered all human being aspects including sports. The invention of new theories and equipments which improve the sport is the real evident that can be seen now. Tennis is one of sports that is progressively developed. There are many tennis clubs come up both in region and national level. At the first time, this game was played by using a palm that swung foward to hit a ball in the large field. Since the knowledge develops continuously, hence, the way of playing this game is also changed by using a racket to hit the ball.

Various reasons and purposes are stated by the experts about playing tennis. One of them is to get an achievement. Based on the rule of National Sport System No.3, year 2005, "an achievement is the result of maksimum effort that is reached by a player or a group of player (team) in sport activity". To get an achievement is not easy. The achievement will be reached if there is cooperation between government, society, also elements which support the sport coaching.

This is similar with what have been revealed by Syafruddin (2011: 57):

"The best player achievement is the result of coaching which is provided to the players through exercises that are programmed well and directed. Achieving the best player achievement is affected by: (1) internal factor is factors derived from the player potency, such as physical strength, technique, tactics, and mental strength. (2) External factor is factors derived from out of the player self, such as, facilities and infrastructures, coach, builder, sport teacher, family, organization, climate, weather, nutritious food and etc."

Based on the explanation, it can be stated that to reach the sport achievement, the directed cooperation is needed also consider all aspects which support in reaching the achievement whether internal and external factors.

In tennis games, there are several types of stroke. However, there are some basic strokes which are commonly used in this game, such as groundstroke, forehand, groundstroke backhand, volley, and service. It is supported by Hendri's explanation (2009:33), who explains several types of basic stroke that are usually used in playing tennis are groundstroke, rally (forehand and backhand), volley, and service. By mastering these strokes, a player is able to play tennis. From the three strokes, one stroke which is essential to be mastered is service. Hendri (2009:58) explains that "service is one type of stroke in the tennis game that is a stroke which is started by tossing the ball first before hitting it.

The reason why service is really important because the service is the opener stroke in the competition. Thus, this stroke is very essential to be mastered. This is in line with Brown's explanation (2007:53), every service is really important since a point will not be obtained without doing service first. Moreover, Hendri (2009:58) states that service is the opener stroke in playing the game. It is also a weapon to get the point. Hence, if the opponent cannot return the service, the server will get the point. By having good service, the chance to win the competition is opened widely. Considering the important of service, this stroke has to be mastered well.

Service, in this case, is flat service. The flat service is a service which is done by particular way in order to make the ball moves straight and does not spin, so the ball movement is relatively faster. The good service is affected by several

1309 IPage councilfor Innovative Research

February $2016 \quad$ ww w. cirworld.com 
factors, such as, the grip strengh, waist flexibility, grip, the impact point, standing position, tossing of the ball, and the racket swing.

The grip strength is one part of stroke technique. If the racket grip is unsteady with the stroke will be done, the player cannot reach the maximum and expected result. Conversely, the stroke which is done by the steady racket grip, the result is relatively well. Therefore, the racket grip technique is very essential to be mastered. This is in line with Yudoprasetio (1981:24), who says that the muscle grip strength has an important role because when the player hits the ball by the racket, the strong muscle grip strength is needed in order to make the racket cannot be loose easily and the stroke result will be directed.

The flexibility is defined as the possibility of maximum movement which can be done by a joint. In Syafruddin (1990:58), the flexibility is body strength to do exercises with big or large amplitude movement. In the tennis game, the movements which expect the maximum work of the joint often happen. For example, the hip joint strength is needed to reach the far ball and the waist flexibility is really needed to turn around the body to make a good position when the stroke will be done. As a result, a player who has the good grip strength and waist felxibility will be able to produce the proper service stroke and able to put the ball to the far sport from the oppenent reach.

The tennis training of State University of Padang (PTL UNP) which has been built in this university since 1997 up to present is led by Drs. Hendri Irawadi, M.Pd. In the development of PTL UNP club, there are many players who have had the achievements both in region and national level. The PTL UNP club has obtained many prestigeous titles from those achievements gotten in the competitions that were followed.

From the observation done by the researcher and the information given by the coach of PTL UNP, Mr. Hendri Irawadi, it can be stated that the players of PTL UNP still are not good at doing the service. It can be seen from many services still are out, hang on the net, and cannot reach on the target. Several factors that were predicted affected the service skill were lack of the hand grip strength and waist flexibility which influenced the accuracy of flat service.

From the component of the achievement obtained as descibed above, there is no obvious information in the training about the contribution of the grip strength and waist flexibility toward the application of the flat service in the tennis game. Based on the explanation, the researcher was interested in conducting a research about the contribution of physical strength on the accuracy of the flat service which was entitled "The contibution of the grip strength and waist flexibility on the accuracy of flat service at the tennis player club of PTL UNP".

\section{B. Research Methods}

This research was one type of correlational research which was aimed to figure out the relationship between independent and dependent variable. The independent variable was the grip strength $\left(X_{1}\right)$ and the waist flexibility $\left(X_{2}\right)$. Meanwhile, the dependent variable was the accuracy of flat service $(Y)$.

The population of this research was the tennis players of PTL UNP club that totaled 35 people. It consisted of 26 males and 9 females. The sample of the research was taken by purposive sampling. The number of the sample was 20 male players.

In line with the purpose of the research that were reached, type of the data in this research was primary data in which the data were gained from the grip strength, waist flexibility and the accuracy of flat service tests on the tennis players of PTL UNP. The data obtained were analyzed by using simple and multiple correlation. The formula as follow:

The coefficient of simple correlation

$$
r x y=\frac{n \cdot \sum x_{1} y-\left(\sum x_{1}\right) \cdot\left(\sum y\right)}{\sqrt{\left\{n \cdot \sum x_{1}^{2}-\left(\sum x_{1}\right)^{2}\right\} \cdot\left\{n \cdot \sum y^{2}-\left(\sum y\right)^{2}\right\}}}
$$

The coefficient of multiple correlation

$$
r_{y_{1.2}}=\sqrt{\frac{r^{2} y_{1}+r^{2} y_{2}-2 \cdot\left(r_{y_{1}}\right)\left(r_{y_{2}}\right)\left(r_{1.2}\right)}{1-\left(\left(_{1.2}^{2}\right)\right.}}
$$

\section{Findings and Discussion}

\section{The Contribution of the Grip Strength $\left(X_{1}\right)$ toward the Flat Service Accuracy $(Y)$ for Tennis Players of PTL UNP}

Based on the result of the hypothesis test analysis, it was found that $t_{\text {count }}(5.43)>t_{\text {table }}(2.101)$ was on the significant degree $\alpha=0.05$ and $\mathrm{dk}(\mathrm{n}-2=18)$. Thus, it was concluded that there was a significant relationship between the grip 
strength and the flat service accuracy of tennis players of PTL UNP. The contribution of the grip strength toward the flat service accuracy was about $62.1 \%$.

From the analysis, it can be concluded that there was a significant relationship between the grip strength and the service accuracy.

Strength is a very important component from the physical condition as a whole because it is the locomotion of each physical activity. According to Rusli (1991:118), "strength is an ability of muscles to do contractions in order to arouse tensions toward a resistance". Hendri (2014:77) says that "strength can be defined as an ability of using forces in the form of lifting or resisting a maximum load". Meanwhile, Arsil (1999:47) mentions "factors that affect someone's strength is 1) the biomechanic factor, 2) the muscle's size factor, 3) the gender factor, and 4) the age factor".

Leary (1988:9) explains that "someone's racket grip affects the surface of the racket when it touches the ball. A proper grip gives comfort to the hands. The comfort feeling of the hands of course helps the player in hitting the ball to the expected direction. The proper grip has to be practiced first in order to be able to swing the racket well".

How the player grips the racket influences the result of the flat service. If the grip is not proper and strong enough onto the racket, then the hit will not be perfect. A strong grip adds strengths to the hit in doing the flat service. Thus, the grip strength is needed in doing the basic service technique which is the throw.

The fingers' muscles are also very essential in hitting the ball especially in making a service. In order to produce the maximum force of the muscles, those several factors have to be paid into attention to prevent problems during the contractions. Understanding the structure of the fingers' muscles helps the player to figure out which muscles are important in doing a hit as well as to figure out the locations of each muscle. The part of the fingers' muscles that work the most during a flat service can also be analyzed. A strong hand grip is very needed when the player swings the racket or during the impact moments of the racket and the ball in which the hand grip is not strong enough so that the ball do not get into the expected direction (the service box).

From those explanations, it is clear that the grip strength is important in tennis aspecially in doing the service. The stronger the grip, the better the service will be. It happens because the grip strength contributes to the flat service accuracy in the game of tennis.

\section{The Contribution of the Waist Flexibility $\left(\mathrm{X}_{2}\right)$ toward the Flat Service Accuracy $(\mathrm{Y})$ for Tennis Players of PTL UNP}

Based on the result of the hypothesis test analysis, it was found that $t_{\text {count }}(5.43)>t_{\text {table }}(2.101)$ was on the significant degree $\alpha=0.05$ and $\mathrm{dk}(\mathrm{n}-2=18)$. Thus, it was concluded that there was a significant relationship between the waist flexibility and the flat service accuracy of tennis players of PTL UNP. The contribution of the waist flexibility toward the flat service accuracy was about $62.1 \%$.

From the result of the analysis, it could be seen that there was a significant relationship between the waist flexibility and the flat service accuracy. The samples' waist flexibility would be better by having exercises. As a result, by having the exercises, it was expected that the flexibility of the waist improved and gave great contribution toward the service accuracy.

Syafruddin (1990:58) says that "flexibility is an ability of the body to do exercises in a great or wide moving amplitude". According to Sayuti (2011:221), "someone's flexibility will make it easier for him to do wider and more free moves toward all directions on the joints and ligamen". In other words, it can be said that flexibility is the ability to do moves toward all directions optimally. It is a physical condition that determine in learning moving skills, avoiding injuries, developing strengths, speed, endurance, and coordination." (Syafruddin (2011:58).

From those explanations given, it is clear that the waist ability is really needed in the game of tennis especially in the doing services. The more flexibel the tennis player, the better the service made because the flexibility contributes to the flat service accuracy in the game of tennis.

\section{The Contribution of the Grip Strength $(\mathrm{X} 1)$ and the Waist Flexibility $\left(\mathrm{X}_{2}\right)$ toward the Flat Service Accuracy $(\mathrm{Y})$ for Tennis Players of PTL UNP}

Before figuring out the contribution of the two variables, then the connection between them have to be known first. In order to know how strong the two variables connect to each other, the multiple correlation formula was used. The formula was also used to figure out the contribution between the grip strength and the waist flexibility toward the flat service accuracy of the tennis players of PTL UNP. The test criteria were significant by using the $F$ test. If $F_{\text {count }}>F_{\text {table, then there was a }}$ contribution given by the two variables toward the flat service accuracy. On the other hand, if $F_{\text {count }}<F_{\text {table, }}$ then there was no contribution given by the two variables toward the flat service accuracy. From the analysis, it was found that the multiple correlation coefficient (the $F$ test) was counted as $F_{\text {count }}(18.34)>F_{\text {table }}(3.59)$ on the significant degree of $\alpha=0.05$ and dk quantifier $(\mathrm{k}=2)$ as well as dk denominator $(n-k-1=17)$. It was concluded that the multiple correlation coefficient in this research was significant. It means that there was a significant contribution among the grip strength and the wait flexibility toward the flat service accuracy of the tennis players of PTL UNP. The contribution of the grip strength and the waist flexibility toward the flat service accuracy was about $68.3 \%$. 
Tennis is a kind of sport that requires good physical conditions. Those conditions include the grip strength and the waist flexibility. Good grip strength and waist flexibility are needed in order to be able to do the flat service in the game of tennis.

The grip strength is one factor that affects the flat service of tennis players because in doing the service, then they are required to have good hand grips in order to produce a maximum service. The players who have good hand grips tend to be able to have good service accuracies.

Beside the grip strength, the waist flexibility is also an important physical condition component in the game of tennis. It is needed in making a service. It determines the success of making the service since it helps the players to make them easier to do wider and more free moves toward all directions on their joints and ligamen. Thus, the players can make a flat service in a proper position and produces a maximum service.

From the analysis, it can also be concluded that the grip strength and the waist flexibility give contributions toward the flat service aaccuracy. It means that the players' service accuracies are affected by their hand grips and their flexibilities.

\section{Conclusions and Suggestions}

Based on the results of the reseach that have been explained before, the conclusions are as follow: 1) the grip strength had a significant relationship toward the flat service accuracy of the tennis players of PTL UNP. It was marked by the $t_{\text {count }}$ $(5.43)>t_{\text {table }}(2.101)$ and the contribution about $62.1 \%$. 2) the waist flexibility had a significant relationship toward the flat service accuracy of the tennis players of PTL UNP. It was marked by the $t_{\text {count }}(5.43)>t_{\text {table }}(2.101)$ and the contribution about $62.1 \%$. 3) the grip strength and the waist flexibility contributed toward the flat service accuracy of the tennis players of PTL UNP. It was marked by the $F_{\text {count }}(18.34)>F_{\text {table }}(3.59)$, with the score of $R=0.827$ resulted the score of $R^{2}=0.683$ and the contribution about $68.3 \%$.

In order to solve problems related to the flat service accuracy, then it is suggested to : 1) the coacnes to apply and pay more attention about the grip strength and the waist flexibility in the training program. 2) the tennis players to pay more attention to the grip strength and the waist flexibility factors in order to be able to do other physical exercises. 3) future researchers to discuss about other factors related to the good service accuracy in the game of tennis.

\section{REFERENCES}

[1]. Arikonto, Suharsimi. (2000). Prosedur Penelitian. Jakarta.

[2]. http://id. Wikepedia.Org/wiki/senam kesegaran jasmani.

[3]. http://elhiiejunid.blogspot.com/2012/05/metode-mengajar-dalam-pendidikan.html

[4]. http://www.academia.edu/483276

[5]. DEFINISI_PENGEMBANGAN

[6]. http://rochimtoatw.blogspot.com/2014/05/normal-0-false-false-false-in-x-none-ar.html

[7]. http://ecampus.fkip.unja.ac.id/eskripsi/data/pdf/jurnal_mhs/artikel/A1D408054_585.pdf

[8]. Irawadi, Hendri.2009. Cara Mudah Menguasai Tenis Lapangan. Malang: Wineka Media

[9]. Sugiyono. 2008. Metode Penelitian Pendidikan Pendekatan Kuantitatif, Kualitatif dan R\&D. Bandung: Alfabeta.

\section{CURICULUM VITAE}

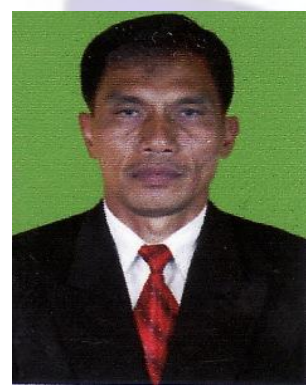

Firdaus Kamal, born in Jambi 12 Novembers 1962, was the second of Mr. H. Sutan Pameran (Alm)and Mrs. Hj. Elzas M. (from Bukittinggi).

Married to Agus nelly and happing a child nam ed Rahmat Al Azi z katialy, Student of PembangunanUNP Senior High School.

Education finish his Prim ary School in SD Negeri 01 Bajubang Jam bi in 1975, High School in Bajubang Jam bi in 1978, Senior Figh School in Bajubang Jam bi in 1981, and Sport Science Faclity, Institute a Science Theacher and Science Education of Padang in 1985, in 1997 continued Megister Program Sport Science in Airlangga Univercity and finisehed 1999, in 2009 continued Doctor

Program Sport Education Studies in Semarang Univercity and finished 2012.

In 1987 appointed School Theacher Gym Teacher and in 1990 m ove d to the transition to Ins titute a Science Theacher and

Science Education of Padang until now.Scientific Activities, Sport Science Thecnology (Scientific Papers, 1998), PB Pelti Instructur (Workshop, 1994), The Role of Secology, Psychology and Sports Bisiness in Supporting the Improvem en of Sports Performence (Sympos ium, 1997), Internas ional Tenis Federation Coaching Works hop (2000), Inters ection Scientific Work of Science and Thecnology of Sports (Workshop, 2007).

Scientific Work (Book), General Science of Sport (UPI Bandung, 2003), Sports Marketing (UPI Bandung, 2006), Sport Management (UPI Bandung, 2008).
1312 | P a g e
council for Innovative Research 